\title{
How teachers can guide students towards the increased use of contextualised MALL in target and non-target countries: The case of L2 Chinese adult students
}

\author{
Orit Ezra \\ Tel Aviv University, Israel
}

\section{Anat Cohen}

Tel Aviv University, Israel

\begin{abstract}
Contextualised mobile assisted language learning (MALL) has been greatly discussed (Pegrum, 2014); however, its potential has not been reached in either target or non-target countries, and this calls for teachers' attention. This study recommended a way for teachers to guide their Chinese second or foreign language students towards increasing their contextualised MALL, by relying on a framework proposed by Cohen and Ezra (2018) and based on the learners' existing activities. The framework's contextualised components include real-world and real-life contexts (a measuring index is proposed), as well as device mobility. The study recommended the following: teachers in target and non-target countries should focus differently on generic and dedicated activities; content factors for dedicated activities should be taken into account; teachers should guide students to relate to the real world and real life, including objects and other core activities. The findings may encourage teachers to guide students without worrying about the extra time spent in an overcrowded curriculum.
\end{abstract}

\section{Implications for practice or policy:}

- Teachers should consider contextualised variables: devices mobility, real-world context level, and real-life context level.

- Teachers in the target country should focus on dedicated mobile activities while tackling places and life needs.

- Teachers in the non-target country should focus on both generic and dedicated mobile activities.

- Teachers can guide students to deal with content factors such as a restricted school curriculum.

Keywords: mobile assisted language learning, MALL, contextualised MALL, Chinese learning, Chinese teaching, mobile learning

\section{Introduction}

Mobile assisted language learning (MALL) has the potential to provide valuable contextualised language learning (e.g., Hwang, Chen, \& Chen, 2011; Hwang \& Chen, 2013). Mobile portability supports learners' engagement with contexts, resulting in a more personalised, meaningful and subsequently deeper (ComasQuinn, Mardomingo, \& Valentine, 2009) or authentic (Stockwell \& Hubbard, 2013) learning experience. Given the importance of contextualised language learning (Comas-Quinn et al., 2009; Wong, Chin, Tan, \& Liu, 2010) and the ability of mobile devices to support it, the value of MALL is apparent. As Comas-Quinn et al. (2009) noted, in a country where a language is spoken (i.e., the target culture or target language country), contextual language learning is ideal because contextual experiences abound. However, mobile contextual learning can also provide context-rich experiences in non-target countries. Therefore, case studies of contextualised MALL have considered both target and non-target language countries (e.g., Chen \& Li, 2010; Ogata et al., 2008).

Exploring two reviews of MALL literature (Burston, 2013, 2015) found that studies have generally examined formal learning programs, where contextualised learning is typically designed by program facilitators; they have not looked at the users' own personal use of mobile devices and how that use relates to MALL. Furthermore, the use of surveys in MALL studies is limited (Duman, Orhon, \& Gedik, 2015), 
but their ability to shed light on a phenomenon is well known (Wingkvist \& Ericsson, 2011). Therefore, probing learners' self-reported mobile activities, whether implemented by their program or by themselves, seems an interesting research direction that could be taken in both target and non-target countries. According to Van Praag and Sanchez (2015), teachers should be aware of the learning options and benefits of mobile technology in the classroom. It may be similarly important for them to learn about students' MALL practices outside the classroom, whether implemented by their teachers or not, if they are to guide their students in maximising contextual MALL learning. Kukulska-Hulme (2017) noted the need to balance technological and human assistance and proposed a mobile pedagogy in which the teacher's role is defined as that of an intelligent assistant, connecting learning within and beyond the classroom. Mobile pedagogy includes self-directed learning alongside an equally important teacher role (Kukulska-Hulme, Norris, \& Donohue, 2015). Therefore, it is necessary to guide students in their mobile learning.

A recurring problem in contextual MALL is what to measure and how to measure it. Many implementation studies (see Burston, 2013) seemed to blur the real-world context and the real-life context. This blurring was addressed by the authors of this article in past studies (Cohen \& Ezra, 2018; Ezra \& Cohen, 2018). They proposed a research framework to define and evaluate contextualised MALL, based on the measurement of three elements: the real-world context level, the real-life context level (for which they built a measuring index), and device mobility. Real-world context pertains to places where the learning occurs and highlights their transformation into a learning context (Pegrum, 2014). Real-life context is important, as it refers to daily life and actual language usage (Reinders \& White, 2010), where learners' learning environment blends with their real-life contexts (Wong, Chin, Tan, \& Liu, 2010). Device mobility represents diversity of place (Pegrum, 2014; Reinders \& Pegrum, 2016). As presenting a diversity of styles in language learning is fundamental to the facilitation of proper communication in various situations (Cai, 2008), diversity of context is imperative.

When the framework was applied to learning Chinese as a second or foreign (L2) language (Ezra \& Cohen, 2018), it was found that learning in the target country was more contextualised than in the non-target country but only in the language learners' generic activities (i.e., no language learning pedagogy). In addition, there was a gap between potential and actual contextualised MALL, particularly in dedicated activities (i.e., with language learning pedagogy) in both target and non-target countries. Thus, investigating contextualised learning in mobile Chinese learning among foreign students of Chinese in target and nontarget countries seems merited. In this study, Taiwan is set as the target country, where the target Chinese language (learners' L2) is the spoken language, and Israel, predominantly a Hebrew (learners' L1) speaking environment, is set as the non-target country.

One worry of teachers is that they will spend extra time guiding students in an outside activity, and this will replace more valuable learning (Shu, 2008a). This study builds on previous findings (Cohen \& Ezra, 2018; Ezra \& Cohen, 2018) to suggest ways for teachers to increase contextualised MALL for learners, specifically Chinese L2 students. To tackle teachers' concerns about how much time they should spend on MALL, the study examined students' activities. It found there is no need to change them; contextualised learning can be incorporated into their present MALL activities, thus minimising or even avoiding extra time spent by either the teachers or the learners.

In short, relying on students' present MALL activities on the one hand, and the contextualised MALL framework and index (Cohen \& Ezra, 2018; Ezra \& Cohen, 2018) on the other hand, this study recommends ways for teachers to guide Chinese L2 students in both target and non-target countries to increase their contextualised MALL learning.

The study aimed to answer the following three research questions:

- Q1. How should target and non-target country teachers focus differently to increase students' contextualised MALL?

- Q2. What factors should teachers address in target and non-target countries to increase students' contextualised MALL?

- Q3. What are the recommendations for teachers to increase students' contextualised MALL in the target and the non-target countries based on the proposed framework and real-world and real-life evaluation index? 


\section{Background}

\section{Learning in the target and non-target countries}

The target language, learnt by students who are native speakers of a different language (L1), is referred to as L2 and involves foreign or second language learning (Burston, 2013). In a foreign language learning environment, the studied language - or the target language - is not the primary vehicle for interaction; thus, language input is limited, and the language is not required for survival. In contrast, in a second language learning environment, the studied language is the main vehicle for communication, its input is abundant, and it is essential for survival (Oxford, 2003).

Scholars agree on the benefits of studying the L2 in the second language learning environment or the target country (e.g., Anderson, Hwang, \& Hsieh, 2008; Comas-Quinn et al., 2009; Petersen, Divitini, \& Chabert, 2008). According to Oxford (2003), the differences between a foreign and a second language learning environment have a crucial effect on factors such as motivation. In the second language learning environment, motivation is typically stronger, whereas in the foreign language learning environment, it may be quite variable. This also applies to contextual MALL comprised of device mobility, real-world context level and real-life context level. As noted above, MALL in the target country is more contextualised, but only for generic activities. There is also a gap between potential and actual contextualised MALL value, particularly in dedicated activities (but also in generic ones). Thus, MALL commonly does not reach its full contextual potential (Ezra \& Cohen, 2018).

\section{Students' dedicated and generic MALL activities}

Reinders and Pegrum (2016) proposed a classification for generic and dedicated mobile materials. Recent work (Ezra \& Cohen, 2018) defined the language learning orientation of dedicated and generic activities as the existence or non-existence of content or pedagogic language learning design orientation in mobile materials (applications, websites, and/or pure content) or in broader learning activity usage. In the study described here, Chinese students' MALL activities, taking place outside of the learners' residence, were classified according to this definition. Generic activities in both the target and the non-target countries were comprised mostly of social communication (e.g., Facebook, WhatsApp, WeChat, Line) between classmates or between students and native speakers, or were stand-alone electronic dictionary activities which did not support any other mobile activity or studying activity such as doing homework. A group of generic activities existing only in the target country corresponded with basic life necessities (e.g., navigating using Google Maps, finding online information such as reviews, bus schedules, city bike locations). Electronic dictionary assistance in studying (i.e., based on materials such as books or handouts) was a common dedicated activity in both the target and the non-target countries. Other common dedicated activities also relatively balanced between the target and non-target countries included listening materials aimed at language learning (such as books, CDs, podcasts or learning videos), flashcard activities (often related with class word lists or other formal vocabulary sources such as HSK - a Chinese formal proficiency test), and educational applications and games.

\section{Contextualised MALL research framework and index}

Integrating previous literature on context (Dey \& Abowd, 1999; Klopfer, 2011; Pegrum, 2014; Reinders \& Pegrum, 2016; Schilit, 1995; Wong et al., 2010), Cohen and Ezra (2018) and Ezra and Cohen (2018) suggested a research framework to define and evaluate contextualised MALL based on device mobility (pertaining to place diversity), real-world context level (pertaining to one's place) and real-life context level (pertaining to one's life). They also proposed an index to quantitatively measure the real-world and reallife contexts.

The real-world context level index is based on both content and place (Figure 1). Thus, a MALL activity can have three real-world context scores: place score, object score and situation score based on the amount (partial or full) of content related to the place, the non-typical or typical objects of the place, and the typical situations at the place. Partial content relationships, or relationships to non-typical objects, receive lower scores. One typical example is the sign case (Cohen \& Ezra, 2018), in which the place and object were both scored 4. Various manifestations appeared (such as parking lot signs). Learners searched their electronic dictionaries for words related to the place which the sign represented and to typical objects of the place - 
namely, the sign attached to the place. However, mere curiosity triggered these incidents, and there do not seem to have been any typical situations.

\begin{tabular}{|c|c|c|c|c|c|}
\hline \multirow{2}{*}{\multicolumn{2}{|c|}{ Factors }} & \multicolumn{4}{|c|}{ 2. Place factor } \\
\hline & & Place (P) & $\begin{array}{l}\text { Non-typical } \\
\text { object (NTO) }\end{array}$ & $\begin{array}{c}\text { Typical } \\
\text { object (TO) }\end{array}$ & $\begin{array}{c}\text { Typical } \\
\text { situation (TS) }\end{array}$ \\
\hline \multirow{3}{*}{$\begin{array}{l}\text { 1. Content } \\
\text { factor }\end{array}$} & $\begin{array}{c}\text { No content } \\
\text { relation }\end{array}$ & 0 & 0 & 0 & 0 \\
\hline & $\begin{array}{l}\text { Some } \\
\text { content } \\
\text { relation }\end{array}$ & 3 & 1 & 3 & 3 \\
\hline & $\begin{array}{l}\text { All content } \\
\text { relation }\end{array}$ & 4 & 2 & 4 & 4 \\
\hline
\end{tabular}

Figure 1. Real-world index (Cohen \& Ezra, 2019, p 178)

Real-world context level categories also classify how learners associate content with place: content (C), in which only the content is related to the real-world context but the learner does not recognise the relationship; learner (L), in which the content is not inherently related to the real-world context but the learner recognises the relationship (self-relations); content and learner (CL), in which the content is related to the real-world context and the learner recognises the relationship (Cohen \& Ezra, 2019).

The real-life context level index represents the degree of the mobile learning activity in relation to the learner's other activities, whose purpose is not learning and where the learner is active (Figure 2). Specifically, an activity can have a real-life score based on the level of assistance, support or contribution of the mobile Chinese learning activity to another (real-life) activity whose purpose (as perceived by the learner) is not learning. The other activity could draw support from the learning activity either without any other supporting tools, such as English or human help, or alongside other supporting tools. The latter activity receives a lower score. The other core activity is the smallest activity found to connect to the mobile learning activity. One typical example is the restaurant case (Cohen \& Ezra, 2018), which scored the highest, 2, and was repeated in places such as restaurants and supermarkets. Learners searched their electronic dictionaries when checking menus and products offered only in Chinese.

\begin{tabular}{ccc}
\hline No support & Support & Support \\
& alongside other & without other \\
& tools (AOT) & tools (WOT) \\
\hline 0 & 1 & 2 \\
\hline
\end{tabular}

Figure 2. Real-life index (Cohen \& Ezra, 2019, p 180)

Scholars' conceptualisations of the skills required by mobile learners include contextual awareness (AlShehri, 2011), mobile literacy (Pegrum, 2014), or new literacies (Kukulska-Hulme, 2006) and mobile awareness (Ezra \& Cohen, 2018). Learners' mobile awareness is particularly important, as context aware sensor-equipped mobile learning systems (Wang, 2004) are gaining momentum. High mobile awareness of 
the real-world context is manifested in CL and particularly in L category's events, where learners see the content relationship on their own. Lower mobile awareness is present in $\mathrm{C}$ events, where learners seem to miss a potential relationship with the environment. Mobile awareness may also be exhibited in real-life contexts when learners relate what first seems irrelevant to their core real-life activities (Ezra \& Cohen, 2018).

This study draws on the authors' previous research and practical conclusions (Cohen \& Ezra, 2018; Ezra $\&$ Cohen, 2018). It synthesises these with new data to inform teachers - in both target and non-target countries - on how to help students increase their contextualised MALL. Without changing course content and relying on their students' existing activities (generic and dedicated) on the one hand, and by using the proposed research framework and index on the other, teachers may be encouraged to guide their students to take advantage of contextualised MALL.

\section{Methodology}

This study is the third stage of comprehensive research in which a quantitative framework and index for contextualised MALL were developed. The present article outlines practical recommendations for teachers on how to increase their students' contextualised MALL based on the framework and index developed during the first two stages of the research, synthesising new with previously found data.

\section{Participants}

This research is based on empirical data collected from 53 Chinese L2 beginner-intermediate students in a university in Taiwan and two universities in Israel (target country and non-target country respectively). The 53 participants were aged 19-59; 24 were males and 29 were females. Notably, the research was conducted according to ethical guidelines. The purpose of the research was presented to the students, and their permission to be interviewed and recorded was sought. It is important to note that the activities were the objects observed in this research, not the students themselves.

\section{Procedure}

The data were obtained from fully structured interviews (conducted between September 2016 and January 2017) on student activities. The recorded interviews, conducted for about an hour to 90 minutes, were faceto-face and, in most cases, were on school premises. In Israel, they were held in Hebrew and in Taiwan they were held in English. During the interviews, the learners reported on their mobile Chinese learning activities during the previous month and outside their homes. They then answered questions on each activity based on the research framework context variables (device mobility, real-world context level and real-life context level). Learners specified the places at which the activity had occurred in the past month and particular occurrences they remembered best. These occurrences were referred to as events. For each event, learners were required to state where the event took place, describe it in detail, express the levels of realworld and real-life contexts according to the questions as guided by the interviewer, and state their arguments for these context level selections.

The study relied on students' recalling their past month's activities and events. As there might be memory limitations and an inherent bias due to self-report methods (Bradburn, Rips, \& Shevell, 1987), if students could not recall specific details of an event, primarily the place, it was not recorded. Furthermore, the interviewer made sure to retrieve activities which the interviewee may have neglected to mention because he or she was uninformed about what is considered mobile learning. A compiled list of activities was predefined and served as an aid to recall for the learners (Sudman \& Bradburn, 1973). It would be beneficial for future studies to employ an online approach to capturing the data. Developing electronic diaries to capture data seems a valuable practical line of work.

\section{Analysis}

The present study is the third stage of a larger research study. The analysis of the first stage was conducted using data on 296 activity types and 519 events (each learner activity may have had a few events occurring in the past month), collected from the 53 respondents; 148 activity types were found in Taiwan and 148 in Israel; 255 events were found in Taiwan and 264 in Israel. The research framework and the qualitative 
methodological strategy employed to build the real-world and real-life index in the first stage were developed and presented in Cohen and Ezra (2018). This qualitative methodology entailed a review of the 519 event descriptions (captured by the recorded interviews) and the adjustment of the initial literaturebased real-world and real-life model based on learners' stories, as well as a compatible index to allow realworld and real-life measurement. An intensive inter-judge reliability process (between the two researchers) established agreement. Thus, the data were evaluated three times: the first as told by the learners, the second and third times as reviewed by the first author and the second author respectively. Next, in the second stage, Ezra and Cohen (2018) applied an operational scale to the real-world and real-life index; along with the device mobility scale, they used quantitative statistical mixed model test to measure the contextualised differences between target and non-target countries, and between generic and dedicated activities, and to test their interactional effects. Elaboration on the methodologies of the first two stages is available in Cohen and Ezra (2018) as well as in Ezra and Cohen (2018).

The study discussed in this article - the third stage of the larger research project - synthesised the conclusions of the authors' previous two stages, with new qualitative findings. To answer Q1, it explored the findings on the differences between the target and non-target countries (Taiwan and Israel). To answer Q2, it examined findings on dedicated activities. To answer Q3, it employed the contextualised MALL framework and the real-world and real-life index.

\section{Results and discussion}

The results answer the three research questions and suggest ways for teachers to increase contextualised MALL in target and non-target countries, by taking advantage of students' existing activities.

\section{Differences in teachers' focus in target and non-target countries with regard to increasing students' contextualised MALL learning}

The authors' previous analysis of mobile learning activities (Ezra \& Cohen, 2018) showed that contextualised MALL was significantly higher in the target country but only in generic activities; furthermore, activities were contextually far from reaching their potential (in both countries), particularly in dedicated activities. This suggests teachers should pay attention to the activities' learning orientation, that is, generic or dedicated.

The recommendations differ for teachers in target and non-target countries. In the target country, to increase contextualised MALL, teachers should focus on dedicated activities whilst encouraging students to tackle more Chinese places and life needs in their generic activities. Teachers can draw support from the students' generic activities (which will become dedicated as teacher pedagogy becomes involved), such as their use of stand-alone dictionaries or their social activities. These will enable them to tap into students' daily lives. Tackling the original dedicated activities (e.g., dictionaries to assist studying, flashcards, listening) may be harder but is especially important in the target country, as rich and abundant opportunities are presently not being used.

In the non-target country, to increase contextualised MALL, teachers should focus on both generic and dedicated activities. As before, in the generic activities, they can draw support from existing generic usages of stand-alone dictionaries and social activities. Even in the non-target country, this study found sign reading and online conversation (with as much Chinese as possible) afforded real-world or real-life context learning. Non-target country teachers can also guide students to apply some generic real-life or real-world ideas that, in this study, were mostly found in the target country, such as using stand-alone dictionaries in restaurants to read menus. Whilst this applies to Chinese restaurants, in one event in Israel, a student joined Chinese visitors and helped translate food items on an Israeli menu. Non-target country teachers can also address daily life necessities, such as Google Maps for navigation, which only appeared in the target country in this study (Taiwan), and think of ways to adapt them in the non-target country. 
Teachers, particularly in the non-target country, certainly need to be creative to come up with rich realworld and real-life contexts, but in doing so, they are likely to get closer to what learners actually want, by tapping into their students' existing activities. Letting the students select the places (for real-world contexts) and activities (for real-life contexts) they wish to study may also lead to higher affective engagement (Masuhara, 2016). Namely, it may increase their emotional reactions, such as being interested in what they do (Fredricks, Blumenfeld, \& Paris 2004), and their agentic engagement, reflecting their contribution to the flow of instruction (Reeve \& Tseng, 2011). The findings of this study suggest that teachers can capitalise on students' own activities, asking them about their mobile activities outside the classroom and using this knowledge for contextualised MALL. They may use the structured interview used in this study to collect student activities (an adapted version for teachers is attached in Appendix 1). They may also use the study's pre-defined list of mobile Chinese learning activities to find activities which interviewees may have neglected to mention if they were uninformed about what is considered mobile learning (Appendix 2). Figure 3 concisely illustrates these recommend actions.

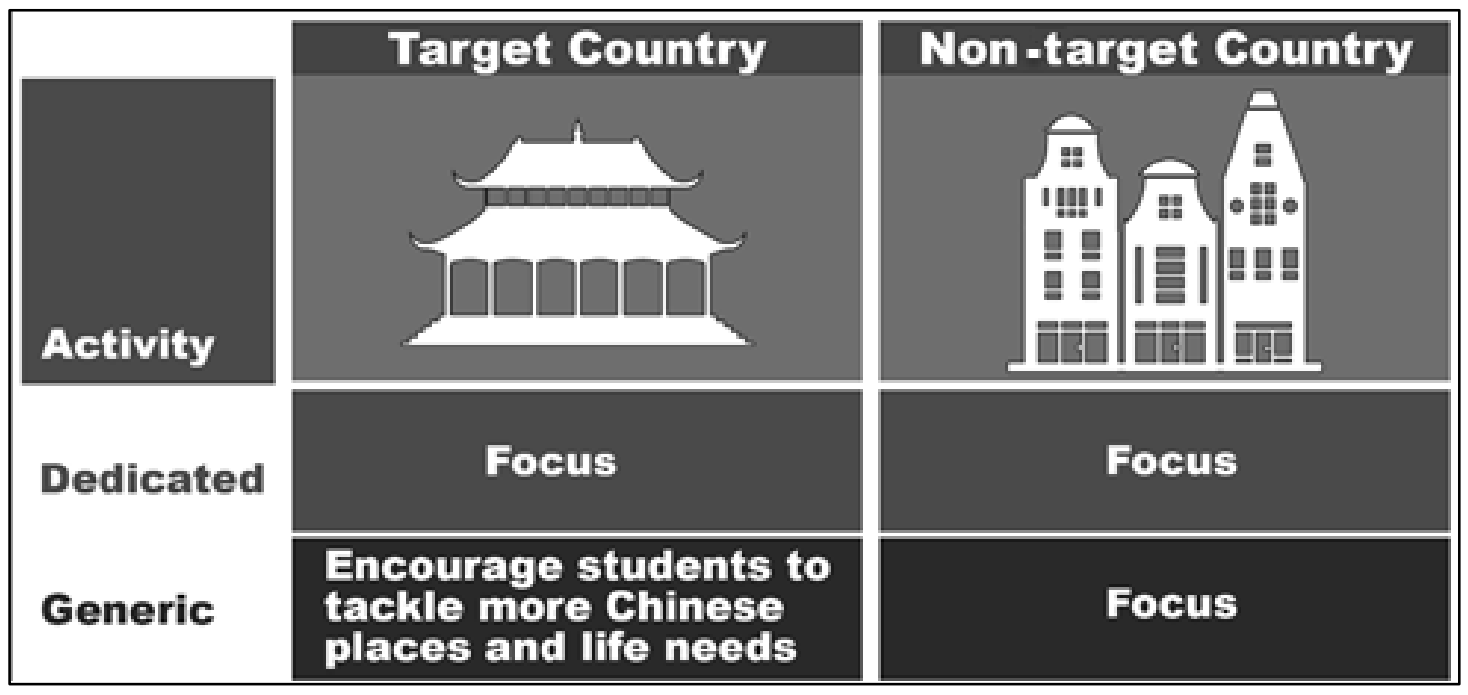

Figure 3. Teachers' focus in target and non-target countries

\section{Factors teachers should address in target and non-target countries to increase students' contextualised MALL}

This study has found that four content factors could inhibit students' dedicated activities from scoring higher in contextualised MALL: restricted curriculum content, lengthy content, inadequate content presentation and lack of affective engagement with content. Teachers can guide their students to deal with these content factors when they are performing dedicated (or generic) activities as follows.

\section{Restricted curriculum content}

Restricted, dedicated materials (Reinders \& White, 2010) used by university students are likely to be limited to institutional curricula and perhaps less related to rich and diversified real-world places or real-life activities. Teachers might be able to expose students to location-based language learning applications, which provide location-based words. However, these did not appear in the study data, and there seem to be few free applications on the market (e.g., Cohen, 2015). Nevertheless, because of the benefits of hooking into an actual curriculum (e.g., Al-Mekhlafi, Hu, \& Zheng, 2009; MASELTOV Project in Pegrum, 2014), teachers should address the restricted content issue, drawing on their own curriculum content, however restricted it may be. Teachers can highlight the potential linkage of students' common generic activities (e.g., stand-alone dictionary, social activities) with the curriculum, and maybe even link common dedicated activities (e.g., curriculum-based assist-studying electronic dictionary, flashcards) with real-world and reallife contexts. For example, they could direct students to check their electronic dictionaries or use, in their social media, those recently learned words that are connected to their real world or that are needed in a reallife activity. Another option is to attempt to use curriculum dialogue words (either checked in the dictionary or practiced with flashcards) in relation to their place or other real-life activities. The following examples from the study data suggest the feasibility of these options: 
- Learner 2 described a generic event wherein a classmate posted a picture of coffee on the social Line application, saying “We just learnt in class how to say 今天晚上我去喝咖啡 [we go for coffee this evening], and the teacher responded “好喝 [tasty]””.

- Learner 15 described a dedicated event of sitting in his family's house and reading the textbook dialogue "My closest family" with the word 决心 [determined]. He said it fit his family members" discussion at the time, and he re-checked the electronic dictionary. He described the event as a "very unusual example, not a very common thing that happens".

- Learner 16 was studying her flashcard words (dedicated activity) while waiting at the doctor's clinic. She described a conversation with a person about where she came from. She explained it was associated with the flashcards she was studying at the time for the lesson "Welcome to Taiwan". She said, "Because we were talking about where I came from and that was what I was studying ... so what I discussed with him was part of what I practiced". She noted some content similarity, such as the words 你国家 [your country], which she used when saying 我的国家 [my country].

Teachers in both countries can guide learners in the real-world context of mobile awareness when performing generic or dedicated activities to increase the real-world context. They can instruct students to notice non-typical objects or, better yet, typical objects and typical situations in a place, even when the content does not seem to be related at first, thus leading them towards the L category (the learner sees relations) of the real-world context. The study found only $23 \mathrm{~L}$ events in both target and non-target countries wherein students related the content on their own, even though the content was not inherently related. The above example of Learner 15 is an illustration of the L category. In the real-life context, there was less evidence of students connecting what seemed to be irrelevant dedicated content. However, Learner 16, described above, who flipped through Chinese flashcards whilst waiting at the doctor's office and exploited some words in small talk, hints at the ability to do so.

\section{Lengthy content}

A closer examination of the common dedicated activities (dictionary, flashcards, listening materials) suggests they contain mostly lengthy content chunks, such as sentences, dialogues, complete chapters, or songs. In activities with a large number of new words, learners may find it difficult to use the context (Shu, 2008b). Thus, in these activities, low real-world context levels (evaluated based on content factor) may be expected. Furthermore, lengthy activities may apply to specific places rather than episodic occurrences (Pegrum, 2014), leading to low device mobility. Teachers can guide students to perform dedicated activities (e.g., assist-studying electronic dictionaries, flashcards, listening materials, and educational games) in smaller word chunks and in varied places to increase the real-world context and device mobility.

Teachers can encourage students to collaborate with other students as much as possible even when absorbed in dedicated activities (smaller chunks may promote this), to share their learning content, thus turning a dedicated activity into a generic activity with potential real-world or real-life contexts. For instance, homework-absorbed students can be encouraged to have peers around (physically or online) to permit a place-related conversation accompanied by the use of an electronic dictionary or a social online conversation (about the place or not) - two examples which appeared in the study data - letting students apply the (non-lengthy) materials they have just studied to these conversations.

\section{Inadequate content presentation}

Course books are presented based on course needs rather than life needs (Masuhara, 2016). Teachers can tackle this by guiding students to notice their real-world places and possibly their real-life activities while performing dedicated activities based on coursework materials. The study found some learners making random relations in the $\mathrm{C}$ (content related) category who were unable to relate the potentially related studied content to their context, thus missing a contextualised learning opportunity. Learner 27, for example, mentioned studying transportation content using flashcards whilst on the train, not intentionally, but simply because of the order of the book chapters. Learner 49 mentioned studying the stroke order for words related to coffee and consumption on a website whilst in a coffee shop, again without a specific purpose, simply coincidentally, and not thinking about the relationship between the words and the coffee shop at the timethe realisation did not come to the learner until later during the interview. Teachers need to guide students towards the CL category (content related and learners see relationships) or, more ambitiously, to learners' self-relations - the L category - which scarcely appeared in the study data (23 events), as these may also 
increase students' mobile awareness (Ezra \& Cohen, 2018). Observing the places (or even activities) may lead to better language noticing, considered beneficial in second language learning (Mitchell, Myles, \& Marsden, 2013).

Lack of affective engagement with content

Immordino-Yang and Damasio (2007) stated that unmemorable knowledge does not transfer well to the real world. Thus, learners' ability to make a connection with the real-world or real-life contexts may be inhibited by their lack of affective engagement with content. Teachers can direct students to connect even unemotional content to the world and real-life contexts, making it more meaningful to them. The example of Learner 15, who connected the word 决心 [determined] in a dialogue about family members to his own family situation, illustrates this. Another example is Learner 32, who talked about being at work and practicing flashcards on a law firm. She said: "The lesson is about submitting a lawsuit and my workplace deserves being sued, they owe money ... I was mentally thinking about it - this workplace should be sued and how to say it". In other words, students can increase their mobile awareness by connecting unemotional content to real-world and real-life contexts. Figure 4 summarises these factors.

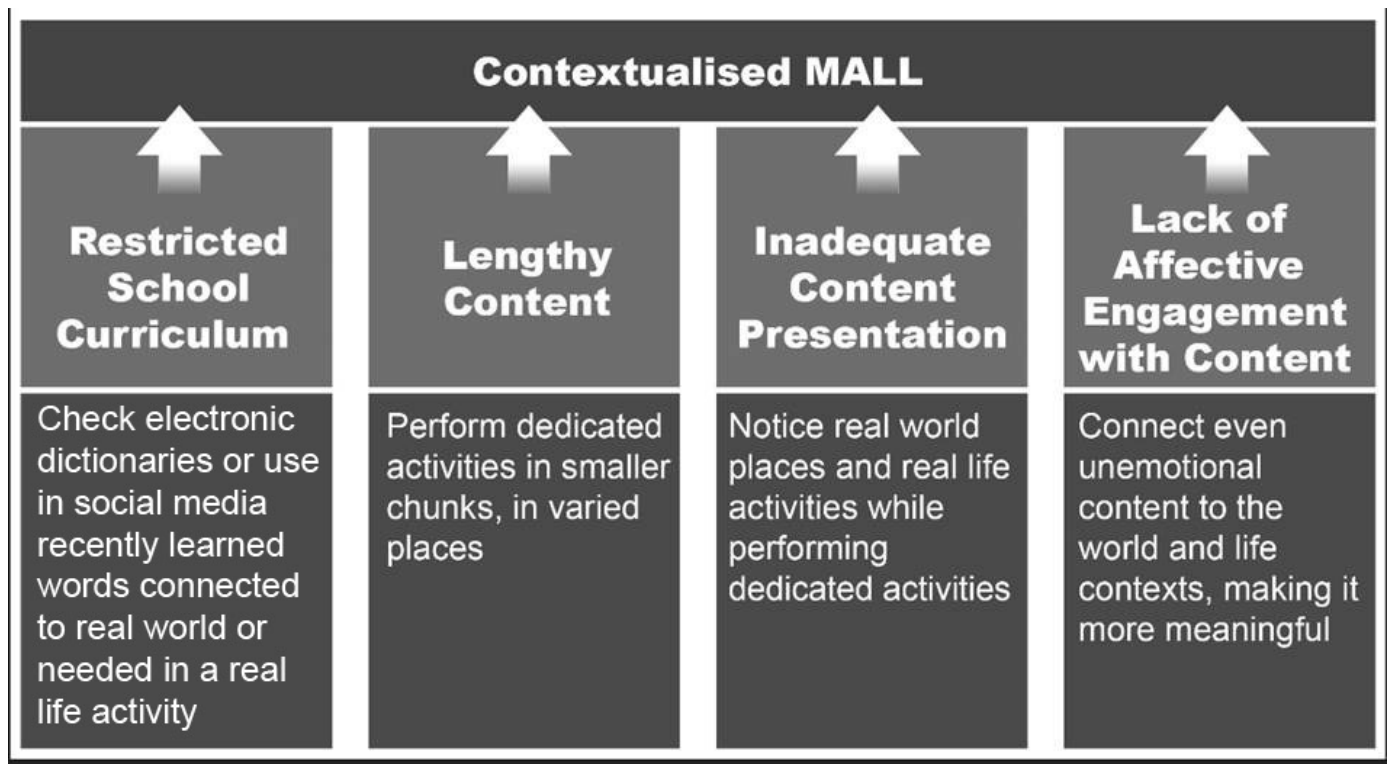

Figure 4. Factors to address to increase students' contextualised MALL

\section{Recommendations for teachers to increase students' contextualised MALL in target and non-target countries based on the proposed framework and the real-world and real-life evaluation index}

This study's analysis of mobile learning activities points to three contextualised variables that teachers should consider: device mobility, real-world context level, and real-life context level. In both target and non-target countries, teachers may draw upon the suggested contextualised MALL framework and realworld and real-life context evaluation index to guide students towards the increased use of contextualised MALL in generic or dedicated activities.

\section{Device mobility}

The study data showed students perform dedicated activities in fixed locations, such as libraries, coffee shops, and transportation vehicles. Common generic activities, such as using the stand-alone electronic dictionary, which were more prevalent in the target country (Taiwan), were often used in similar places such as restaurants (Ezra \& Cohen, 2018). Teachers can therefore guide their students to diversify the locations of their dedicated and generic activities.

Real-world context level

Teachers can guide their students to note the content relations between dedicated or generic MALL activities and a place, the objects of the place (especially typical objects) and typical situations at the place. 
Some more refined aspects that teachers need to take into consideration were revealed by the data analysis; they include the following:

- Numerous objects and situations - Teachers can guide their students to note content relationships, with as many typical objects of the place and as many typical situations at the place. Some examples that stand out in the study data are the following. Learner 20 was at the pharmacy, checking the details of a promotion offer while shopping (object 1), as well as the details of a coupon received when paying (object 2), whilst drawing support from an electronic dictionary. Learner 24 was at a tea house checking the menu items while ordering (situation 1), whilst also having a conversation with friends about the menu items and about tea in general (situation 2), alongside drawing assistance from an electronic dictionary. In these two examples, the typical objects or typical situations to which the content was related were numerous. In other cases mentioned by the learners, there were fewer typical objects or situations; for example, a learner might use the dictionary to check a single item in the pharmacy or to scan a menu.

- Non-Chinese contexts - An important note for teachers, particularly in non-target countries, is the ability to relate Chinese MALL content to non-Chinese contexts. In an example of a student in Israel, Learner 42 was riding the bus and listening to a YouTube song, which included a number of polite words, such as 没关系，对不起 [that's all right, excuse me]. The learner was also able to relate these to the place: "I really used the words when I got off the bus, I thought about it ... because in the bus I thought it was possible to say 对不起 [excuse me] and 没关系 [that's all right]". This example illustrates the ability of learners to see relations by themselves (i.e., selfrelations), as part of the real-world L category of content relations. Notably, the situation also required high mobile awareness (Ezra \& Cohen, 2018). Teachers who direct students to integrate Chinese and non-Chinese practices can help them achieve higher mobile awareness.

\section{Real-life context level}

Teachers can guide their students to use dedicated or generic MALL activities to support other real-life core activities whose purpose is not learning, at least not as perceived by the learners, and where learners are active. Preferably, students should be recommended to use as few supporting tools as possible, especially if they feel they may be redundant, thus avoiding some tools mentioned in this study, such as English assistance on menus or in online conversations; human help in stores looking for information; drawings on packages in the supermarket; and pointing at products in a store. Analysis of the data also revealed the following more refined aspects that teachers need to take into consideration:

- Numerous other core activities - Teachers can direct their students to notice many other activities, leading them to use MALL to support as many other core activities as possible. In this study, for example, some learners reported using MALL activity assistance in only one core activity. Learner 17 used electronic dictionary assistance only to order a knife at a restaurant. Learner 10 was studying weekend activities using an electronic dictionary and having a conversation at the same time with a friend about her own weekend activities. She used the MALL activity for her real-life conversation, but only for the parts on weekend activities. She should be encouraged to use it in other parts of her conversation (if needed, of course). Other learners described more core activities combined in an event supported by their MALL activity. For instance, Learner 16 described using an electronic dictionary not only to help read menu items but also to assist in reading some bill items such as the service charge. Similarly, Learner 6 described using the Line application to schedule an event and to plan the event menu; Learner 23 handled a Line conversation entirely in Chinese, not only to schedule a meeting but also to set up the plan for the meeting.

- Portion of MALL activity supporting another real-life activity - Teachers can guide students to use as much content as possible from their MALL activities to support their real-life activities. This is aligned with the above-mentioned guidelines on tackling the lengthy content factor in dedicated activities, by reducing them to smaller learning content chunks. For example, while she was waiting at the doctor's office, Learner 16 practiced her flashcards for various lessons and used words related to one of the lessons ("Welcome to Taiwan") to communicate with another person. She stressed: "I was talking about where I came from and that was what I was studying ... so what I discussed to him was part of what I practiced ... it was only a tiny portion".

- Essential and non-essential MALL - Teachers can explain to students that even when they are absorbed in other real-life activities that essentially do not require the support of a MALL activity, 
such as using an electronic dictionary, despite the obvious existence of other supporting tools such as an English menu or the possibility of pointing, students should still be encouraged to leverage MALL. For example, Learner 18 discussed buying food at the school cafeteria. Even though he could have pointed at an item, he used an electronic dictionary:

I could have ordered without it... I could just ask them how to read it, how to order it ... I was just curious how it is said, I could have just said oh what is this and then order without searching ... because I used it after all, I will try to remember the character next time when I go there ... I think not essential to use the Chinese app to do these activities.

- Importance of other core activities - Given the importance of meaningful or personally significant information to learners (Ghosn, 2016), teachers can guide students to use MALL in other real-life core activities, especially those which are particularly meaningful. However, less meaningful but still personal activities can be tapped into as well. For example, Learner 16 talked about buying makeup and checking her electronic dictionary to understand a salesperson's explanation of a store offer. She noted that it was not her intention to buy the sale item, and that she was in the store for another purpose, but she did not want to insult the person and thus checked her dictionary to enable the conversation.

- MALL during real-life activities - Teachers can guide their students to apply MALL to support other real-life activities as they are happening; otherwise, according to the real-life index, MALL may remain detached from the real-life context. In Israel, several students consulted an electronic dictionary after an activity took place, thus not allowing the dictionary to support them when it was really necessary and not contextualising their real-life learning. For example, Learner 33 assisted Chinese travellers on a train and looked at the dictionary after the event had ended; Learner 28 was walking in the street when she remembered words she needed (in the past) when she was in a hotel working with Chinese travellers.

- Non-Chinese contexts - As in the real-world context, an important note for teachers, particularly in non-target countries, is to relate Chinese MALL to non-Chinese real-life activities. In Israel, Learner 34 read a Chinese learning post about Singles Day on a social media site and instigated a conversation with friends (in Hebrew) about the post. This example also illustrates this learner's ability to see relations on his own (self-relations), as expressed in the real-world L category of content relations, something which requires high mobile awareness. Teachers directing students to integrate Chinese and non-Chinese practices in real-life can help them to achieve higher mobile awareness. Figure 5 summarises recommendations on how teachers can increase students' contextualised MALL based on the proposed framework and the real-world/real-life evaluation index.

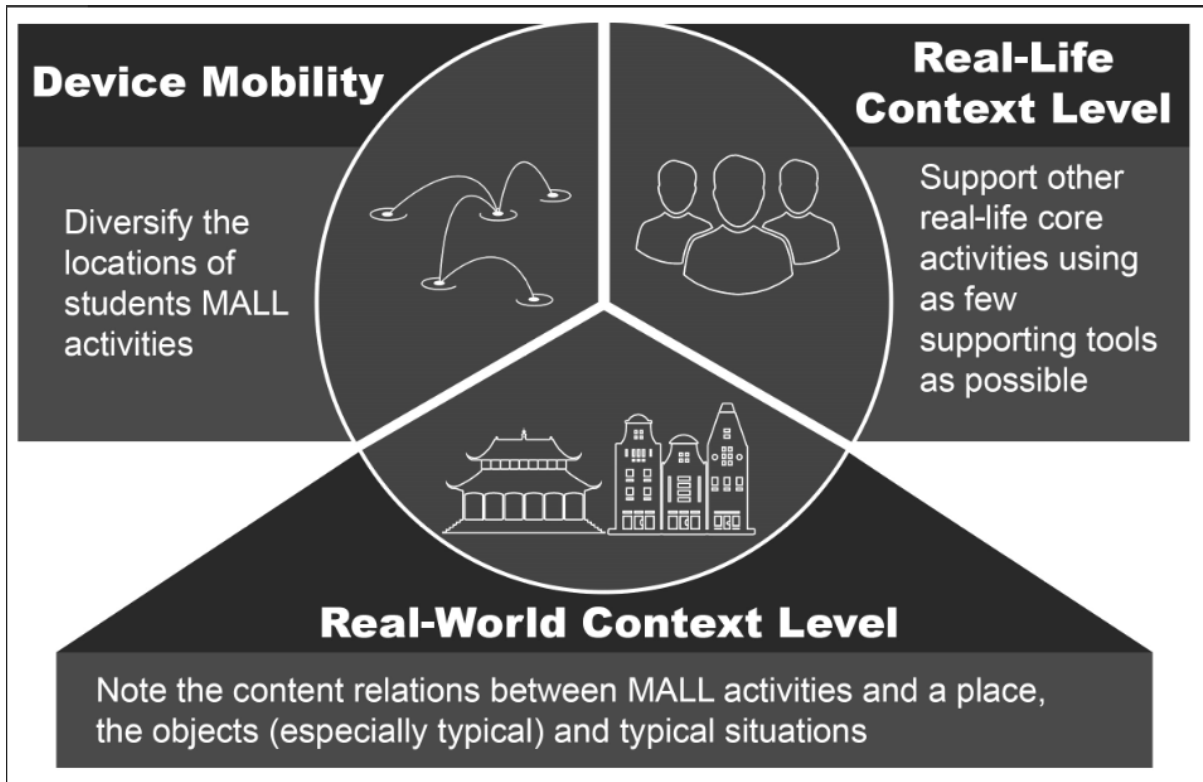

Figure 5. Increase contextualised MALL based on the proposed framework and the real-world and real-life evaluation index 


\section{Conclusion}

Contextualised MALL has not yet reached its full potential (Ezra \& Cohen, 2018). In addition, contextualised MALL case studies are generally drawn from formal learning programs where contextualised learning, if it exists, is typically designed by program facilitators (Burston, 2013, 2015). However, equipping teachers with knowledge about students' MALL activities should encourage them to help students increase their contextual MALL learning. This paper provides some practical suggestions on how to increase contextualised MALL by taking advantage of students' existing activities. Teachers should not worry about having to spend extra time, a major resource when the curriculum is already overcrowded because of the difficulty of the Chinese language (Spencer, 2015). Instead of losing time, they will gain a valuable learning space (Shu, 2008a).

This paper calls for teachers' attention to three themes with practical implications: the differences in teachers' focus in target and non-target countries; content factors which teachers should address in target and non-target countries; and recommendations for teachers in target and non-target countries based on the proposed framework and real-world and real-life evaluation index. These themes are based on research and practical conclusions of a comprehensive study of Chinese L2 students in Taiwan and Israel (Cohen \& Ezra, 2018; Ezra \& Cohen, 2018), synthesised with new data presented in this paper.

The study demonstrated the three themes using data gathered on students' existing activities, but teachers are encouraged to explore their own students' actual activities to employ the themes. Teachers interested in exploring students' activities could begin by using this study's structured interview and activities checklist (Appendix 1 and 2 respectively). It is our hope that the themes will be read by pre-service and inservice teachers of Chinese as a second language. A summary of the three themes follows.

In the target country, teachers can guide students to increase their dedicated MALL activities contextualised learning, whilst encouraging them to tackle more Chinese real-world and real-life contexts using their generic activities. In the non-target country, to increase contextualised MALL, teachers can tackle both generic and dedicated activities. Specifically, this study found four potential content factors that could inhibit the students' dedicated activities from scoring higher in contextualised MALL: restricted curriculum content, lengthy content, inadequate content presentation and lack of affective engagement with the content. Teachers finding creative ways to overcome these problem areas when guiding students in their dedicated (and even generic) activities can help them increase their mobile awareness as exhibited in the L category, in which content which appears unrelated to the real-world context is seen as related by the learners themselves.

Teachers could draw upon the suggested contextualised MALL framework and real-world and real-life context evaluation index (Cohen \& Ezra, 2018), keeping the following in mind: device mobility - guiding their students to diversify the locations where they perform dedicated or generic activities; real-world context - guiding their students to note the relations between the place and dedicated or generic MALL activities' content ; real-life context - guiding their students to use dedicated or generic MALL activities to support other real-life core activities whose purpose is not learning, or are not perceived as such by the learners. By doing this, teachers may also increase their students' mobile awareness, for instance, by having their students self-relate non-Chinese place or life activity content to their MALL activities, as exhibited in the L category events.

\section{Research and practical contributions}

The context-oriented student guidance suggested in this paper can help teachers implement a mobile pedagogy. Kukulska-Hulme (2017) noted the need to balance technological and human assistance and proposed a mobile pedagogy in which the teacher's role is defined as that of an intelligent assistant offering personalisation, designing outside-of-classroom activities and connecting learning within and beyond the classroom. Features of this mobile pedagogy were elaborated by Kukulska-Hulme et al. (2015) and included self-directed learning alongside an equally important teacher role. Accordingly, good language learning practices, such as asking learners which tools they might use and asking them to reflect on their appropriateness, employing open tasks and working on evolving learning needs, and having learners select tools and content, are all recommended. The contextualised-oriented guidance suggested here relies on 
student activities and on teachers' knowledge of how to increase contextualised learning using those activities. Ideally, teachers will develop their intelligent assistance capabilities by developing their mobile awareness.

This paper suggests that teachers establish a constructive discourse in which learners and teachers actively collaborate to discuss learners' activities and construct ways to increase their contextualised learning, thus increasing both teachers' and learners' mobile awareness. This suggestion draws on Kukulska-Hulme et al.'s (2015) mobile pedagogy for language learning, which is based on the belief that teachers and learners are active participants in making and shaping language learning. Learners take responsibility for their own learning, and teachers play a part in enabling it. Congruent with a social constructivist approach to learning, which advocates that learners' individual knowledge is mediated through language interaction with others (Jones \& Brader-Araje, 2002), such a discourse in itself may promote language learning, and specifically social constructivist learning, which has been largely embraced by language leaning theories in recent decades (Wong et al., 2010).

Teachers' and learners' mobile awareness is particularly important, considering scholars' assertions that the guidance students receive on how to continue learning a language outside of the classroom has remained relatively the same over time; beginner students, for instance, are expected to dedicate time to practice exercises and use flashcards for vocabulary learning (Purushotma, 2005). The guidance suggested in this paper crosses these boundaries by elaborating, for example, on how these flashcards could be used to increase contextualised learning.

Given the need to define the teacher's important roles and considering the concerns about teachers being replaced by artificial intelligence, and since mobile assistance should work in harmony with and complement the human assistance (Kukulska-Hulme, 2017), this paper's concrete suggestions are timely. Teachers' mobile awareness and subsequently learners' mobile awareness, facilitated by the paper's suggestions, are also particularly important, as context aware sensor-equipped mobile learning systems (Wang, 2004) are presumably still gaining momentum.

\section{References}

Al-Mekhlafi, K., Hu, X., \& Zheng, Z. (2009). An approach to context-aware mobile Chinese language learning for foreign students. In X. Hu, E. Scornavacca, \& Q. Hu (Eds.), Proceedings of the 2009 Eighth International Conference on Mobile Business (pp. 340-346). Piscataway, NJ: IEEE. https://doi.org/10.1109/ICMB.2009.65

Al-Shehri, S. (2011). Context in our pockets: Mobile phones and social networking as tools of contextualizing language learning. In S. Yu (Ed.), Proceedings 10th World Conference on Mobile and Contextual Learning (mLearn) (pp. 278-286). Beijing, China: Beijing Normal University.

Anderson, T. A., Hwang, W., \& Hsieh, C. (2008). A study of a mobile collaborative learning system for chinese language learning. In B. Chang \& H. So (Eds.), Proceedings of International Conference on Computers in Education (pp. 217-222). Taipei, Taiwan: ICCE.

Bradburn, N. M., Rips, L. J., \& Shevell, S. K. (1987). Answering autobiographical questions: The impact of memory and inference on surveys. Science, 236(4798), 157-161. https://doi.org/10.1126/science.3563494

Burston, J. (2013). Mobile-assisted language learning: A selected annotated bibliography of implementation studies 1994-2012. Language Learning \& Technology, 17(3), 157-225. https://doi.org/10125/44344

Burston, J. (2015). Twenty years of MALL project implementation: A meta-analysis of learning outcomes. ReCALL, 27(1), 4-20. https://doi.org/10.1017/S0958344014000159

Cai, Y. (2008). Chinese language teaching material editing writing and introduction. In S. He, X. Zhang, L. Chen, Z. Shu, Y. Cai, \& M. Lai (Eds.), Introduction to teaching Chinese as a foreign language (pp. 113-132). Taipei, Taiwan: Sanmin.

Chen, C. M., \& Li, Y. L. (2010). Personalised context-aware ubiquitous learning system for supporting effective English vocabulary learning. Interactive Learning Environments, 18(4), 341-364. https://doi.org/10.1080/10494820802602329

Cohen, A. (2015, July 19). The real best apps for learning a language [Blog post]. Brainscape. Retrieved from https://www.brainscape.com/blog/2011/11/the-real-best-apps-for-learning-a-language/ 
Cohen, A., \& Ezra, O. (2018). Development of a contextualised MALL research framework based on L2 Chinese empirical study. Computer Assisted Language Learning, 31(7), 764-789. https://doi.org/10.1080/09588221.2018.1449756

Cohen, A., \& Ezra, O. (2019). Contextualised MALL in target and non-target country: Mobile activities evaluation. In A. Forkosh Baruch \& H. Meishar Tal (Eds.), Mobile technologies for organizational learning (pp. 170-191). Hershey, PA: IGI Global. https://doi.org/10.4018/978-1-5225-8106-2.ch009

Comas-Quinn, A., Mardomingo, R., \& Valentine, C. (2009). Mobile blogs in language learning: Making the most of informal and situated learning opportunities. ReCALL, 21(01), 96-112. https://doi.org/10.1017/S0958344009000032

Dey, A. K., \& Abowd, G. (1999). Towards a better understanding of context and context-awareness (Technical Report). Retrieved from ftp://ftp.cc.gatech.edu/pub/gvu/tr/1999/99-22.pdf

Duman, G., Orhon, G., \& Gedik, N. (2015). Research trends in mobile assisted language learning from 2000 to 2012. ReCALL, 27(2), 197-216. https://doi.org/10.1017/S0958344014000287

Ezra, O. \& Cohen, A. (2018). Contextualised MALL: L2 Chinese students in target and non-target country. Computers \& Education, 125, 158-174. https://doi.org/10.1016/j.compedu.2018.06.011

Fredricks, J. A., Blumenfeld, P. C., \& Paris, A. H. (2004). School engagement: Potential of the concept, state of the evidence. Review of Educational Research, 74(1), 59-109. https://doi.org/10.3102/00346543074001059

Ghosn, I. (2016). No place for coursebooks in the very young learner classroom. In B. Tomlinson (Ed.), $S L A$ research and materials development for language learning (pp. 50-66). New York, NY: Routledge.

Hwang, W. Y., Chen, C. Y., \& Chen, H. S. (2011). Facilitating EFL writing of elementary school students in familiar situated contexts with mobile devices. In S. Yu (Ed.), Proceedings of the 10th World Conference on Mobile and Contextual Learning (mLearn2011) (pp 15-23). Beijing, China: Beijing Normal University.

Hwang, W. Y., \& Chen, H. S. (2013). Users' familiar situational contexts facilitate the practice of EFL in elementary schools with mobile devices. Computer Assisted Language Learning, 26(2), 101-125. https://doi.org/10.1080/09588221.2011.639783

Immordino-Yang, M. H., \& Damasio, A. (2007). We feel, therefore we learn: The relevance of affective and social neuroscience to education. Mind, Brain, and Education, 1(1), 3-10. https://doi.org/10.1111/j.1751-228X.2007.00004.x

Jones, M. G., \& Brader-Araje, L. (2002). The impact of constructivism on education: Language, discourse, and meaning. American Communication Journal, 5(3), 1-10. Retrieved from http://acjournal.org/journal/vol5/iss3/special/jones.pdf

Klopfer, E. (2011). Foreword/Preface. In S. Dikkers, J. Martin, \& B. Coulter (Eds.), Mobile media learning: Amazing uses of mobile devices for learning. (pp. 1513-1515) Pittsburgh, PA: ETC Press.

Kukulska-Hulme, A. (2006). Mobile language learning now and in the future. In P. Svensson (Ed.), From vision to practice: Language learning and IT (pp. 295-310). Härnösand, Sweden: Swedish Net University (Nätuniversitetet).

Kukulska-Hulme, A. (2017, May). Mobile and intelligent assistants in education. Keynote presentation at the Media Education Conference, Rovaniemi, Finland.

Kukulska-Hulme, A., Norris, L., \& Donohue, J. (2015). Mobile pedagogy for English language teaching: A guide for teachers. London, United Kingdom: British Council.

Masuhara, H. (2016). Brain studies and materials for language learning. In B. Tomlinson (Ed.), SLA research and materials development for language learning (pp. 23-32). New York, NY: Routledge.

Mitchell, R., Myles, F., \& Marsden, E. (2013). Second language learning theories. London, United Kingdom: Routledge. https://doi.org/10.4324/9780203770795

Ogata, H., Hui, G. L., Yin, C., Ueda, T., Oishi, Y., \& Yano, Y. (2008). LOCH: Supporting mobile language learning outside classrooms. International Journal of Mobile Learning and Organisation, 2(3), 271-282. https://doi.org/10.1504/IJMLO.2008.020319

Oxford, R. L. (2003). Language learning styles and strategies: Concepts and relationships. International Review of Applied Linguistics in Language Teaching, 41(4), 271-278. https://doi.org/10.1515/iral.2003.012

Pegrum, M. (2014). Mobile learning: Languages, literacies and cultures. Basingstoke, United Kingdom: Palgrave Macmillan.

Petersen, S. A., Divitini, M., \& Chabert, G. (2008). Identity, sense of community and connectedness in a community of mobile language learners. ReCALL, 20(3), 361-379.

https://doi.org/10.1017/S0958344008000839 
Purushotma, R. (2005). Commentary: You're not studying, you're just ... Language Learning \& Technology, 9(1), 80-96. https://doi.org/10125/44010

Reeve, J., \& Tseng, C. M. (2011). Agency as a fourth aspect of students' engagement during learning activities. Contemporary Educational Psychology, 36(4), 257-267. https://doi.org/10.1016/j.cedpsych.2011.05.002

Reinders, H., \& Pegrum, M. (2016). Supporting language learning on the move. An evaluative framework for mobile language learning resources. In B. Tomlinson (Ed.), SLA research and materials development for language learning (pp. 116-141). New York, NY: Routledge.

Reinders, H., \& White, C. (2010). The theory and practice of technology in materials development and task design. In N. Harwood (Ed.), English language teaching materials: Theory and practice (pp. 5880). New York, NY: Cambridge University Press.

Schilit, W. N. (1995). A system architecture for context-aware mobile computing (Doctoral dissertation, Columbia University, New York, NY). Retrieved from https://dl.acm.org/citation.cfm?id=220826

Shu, Z. (2008a). Chinese language multimedia and digital teaching. In Introduction to teaching Chinese as a foreign language (pp. 281-299). Taipei, Taiwan: Sanmin.

Shu, Z. (2008b). Chinese language training and teaching material for listening and speaking. In S. He, X. Zhang, L. Chen, Z. Shu, Y. Cai, \& M. Lai (Eds.), Introduction to teaching Chinese as a foreign language (pp. 231-257). Taipei, Taiwan: Sanmin.

Spencer, W. A. (2015). Mandarin Chinese as a second language: A review of literature (Honors Research Projects. 210). Retrieved from http://ideaexchange.uakron.edu/honors research projects/210

Stockwell, G., \& Hubbard, P. (2013). Some emerging principles for mobile-assisted language learning. Monterey, CA: The International Research Foundation for English Language Education. Retrieved from http://www.tirfonline.org/wpcontent/uploads/2013/11/TIRF_MALL_Papers_StockwellHubbard.pdf

Sudman, S., \& Bradburn, N. M. (1973). Effects of time and memory factors on response in surveys. Journal of the American Statistical Association, 68(344), 805-815. https://doi.org/10.1080/01621459.1973.10481428

Van Praag, B., \& Sanchez, H. S. (2015). Mobile technology in second language classrooms: Insights into its uses, pedagogical implications, and teacher beliefs. ReCALL, 27(3), 288-303. https://doi.org/10.1017/S0958344015000075

Wang, Y. K. (2004). Context awareness and adaptation in mobile learning. In B. Werner (Ed.), Proceedings of the 2nd IEEE International Workshop on Wireless and Mobile Technologies in Education (pp. 154-158). Piscataway, NJ: IEEE. https://doi.org/10.1109/WMTE.2004.1281370

Wingkvist, A., \& Ericsson, M. (2011). A survey of research methods and purposes in mobile learning. International Journal of Mobile and Blended Learning (IJMBL), 3(1), 1-17. Retrieved from https://www.learntechlib.org/p/187005/

Wong, L. H., Chin, C. K., Tan, C. L., \& Liu, M. (2010). Students' personal and social meaning making in a Chinese idiom mobile learning environment. Educational Technology \& Society, 13(4), 15-26. Retrieved from https://www.j-ets.net/collection/published-issues/13 4

Corresponding author: Anat Cohen, anatco@tauex.tau.ac.il

Copyright: Articles published in the Australasian Journal of Educational Technology (AJET) are available under Creative Commons Attribution Non-Commercial No Derivatives Licence (CC BY-NC-ND 4.0). Authors retain copyright in their work and grant AJET right of first publication under CC BY-NC-ND 4.0.

Please cite as: Ezra, O., \& Cohen, A. (2020). How teachers can guide students towards the increased use of contextualised MALL in target and non-target countries: The case of L2 Chinese adult students. Australasian Journal of Educational Technology, 36(2), 137-154. https://doi.org/10.14742/ajet.5015 


\section{Appendixes}

Appendix 1 - Collecting students' mobile Chinese activities interview form

\section{A. General questions}

1. Mark the technological devices which you use in order to learn/practice/use Chinese in the country you study (e.g., Israel, Taiwan) (formally and non-formally) within the last few weeks-not more than a month (you may mark more than 1 ):

\begin{tabular}{|l|l|l|l|}
\hline$\square \quad \begin{array}{l}\text { Personal computer } \\
\text { (PC) - desktop } \\
\text { computer }\end{array}$ & $\begin{array}{l}\text { TV (or DVD } \\
\text { devices) }\end{array}$ & $\begin{array}{l}\text { Portable computer } \\
\text { - laptop; notebook }\end{array}$ & Smart phone \\
\hline $\begin{array}{l}\text { Portable audio } \\
\text { device (such as } \\
\text { ipod) }\end{array}$ & $\begin{array}{l}\text { Tablet (such as } \\
\text { ipad) }\end{array}$ & $\begin{array}{l}\text { Electronic book } \\
\text { reader (such as } \\
\text { Kindle device) }\end{array}$ & \begin{tabular}{l}
$\square \quad \begin{array}{l}\text { Car audio devices } \\
\text { or other car } \\
\text { instruments (such } \\
\text { as GPS) }\end{array}$ \\
\hline $\begin{array}{l}\text { Other devices - } \\
\text { please specify }\end{array}$
\end{tabular} \\
\hline
\end{tabular}

2. Now we shall focus on the mobile devices: 


\section{B. Questions about modes of learning the language using the mobile devices (using} applications, websites or other content)

Thoroughly think about all your main mobile device activities (types) in the country you study (e.g., Israel, Taiwan) - outside of your house (there may be activities which are held both at your house and outside) - for the purpose of learning/practicing/using Chinese. Specify the main activities (types). (For the last few weeks-not more than a month)

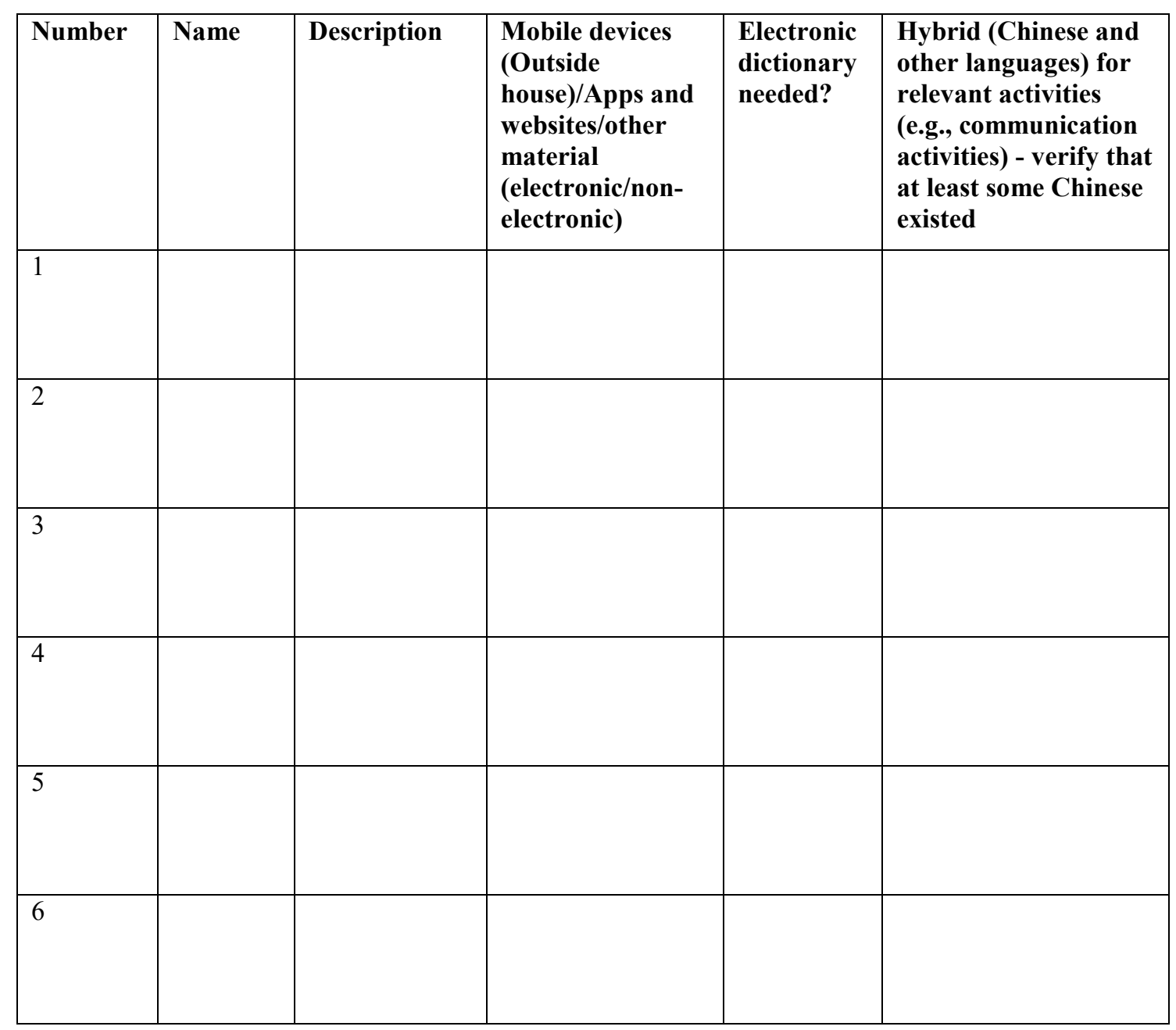


Appendix 2 - Pre-defined list of possible mobile Chinese learning activities

A list of possible activities was compiled from a pilot study conducted before the current study. In this pilot, the participants (free beginner-to-intermediate Chinese learners) were encouraged to describe as many events as they could recall of their mobile activity during the past half year. The list of possible mobile Chinese learning activities shown below was created from the pilot study.

\begin{tabular}{|c|c|}
\hline & Examples \\
\hline $\begin{array}{l}\text { Dedicated language learning } \\
\text { mobile materials }\end{array}$ & $\begin{array}{l}\text { - Internet websites: dedicated to learning Chinese (electronic } \\
\text { dictionaries assisting in studying based on materials such as } \\
\text { book or class handouts, language learning websites, } \\
\text { language exchange websites, etc.) } \\
\text { Applications: dedicated to learning Chinese (electronic } \\
\text { dictionaries assisting in studying based on materials such as } \\
\text { book or class handouts, language learning apps, language } \\
\text { exchange apps, etc.) }\end{array}$ \\
\hline $\begin{array}{l}\text { Generic language learning mobile } \\
\text { materials }\end{array}$ & $\begin{array}{l}\text { - Internet websites: generic websites (newspapers, shopping } \\
\text { websites, social networks, etc.) } \\
\text { Applications: generic applications (WhatsApp, WeChat, } \\
\text { Line; instant messaging; social networks such as Facebook, } \\
\text { Twitter, Instagram. etc.; email; digital books; etc.) }\end{array}$ \\
\hline Group learning & $\begin{array}{l}\text { - Language exchange, group learning (accompanied by mobile } \\
\text { phone) }\end{array}$ \\
\hline More specific & $\begin{array}{l}\text { - Podcasts, YouTube, listening materials such as book CDs, } \\
\text { games, activities initiated by the teacher or where teacher is } \\
\text { involved, virtual reality, augmented reality }\end{array}$ \\
\hline
\end{tabular}

